\title{
Partitional Harmony: The Partitioning of Pitch Spaces
}

\author{
*Marco Feitosa \\ Federal University of Rio de Janeiro (UFRJ) \\ marco.feitosa@ufrj.br
}

Orcid: 0000-0001-8754-2352

DOI: $10.46926 /$ musmat.2020v4n2.01-27

\begin{abstract}
In this preliminary work, we seek to present a brief historical review of the use of partitions in music, to provide a concise introduction to the theory of partitions, and lastly, through an extensive bibliographic revision and a thoughtful theoretical reflection, to lay the foundations of what we call partitional harmony - a comprehensive harmonic conception which relates the theory of partitions to several fields of post-tonal music theory. At the end, some basic operations (pitch, transposition, inversion, and multiplication) are defined and an illustrative musical application is provided, followed by our research prospects.
\end{abstract}

Keywords: Post-Tonal Music Theory. Pitch-Class Set Theory. Pitch Spaces. Theory of Partitions. Partitional Harmony.

Sed omnia in mensura et numero et pondere disposuisti.

Liber Sapientiae, 11:20

\section{INTRODUCTION}

artitions ${ }^{1}$ play important roles in several areas of mathematics such as combinatorics, Lie theory, representation theory, mathematical physics, theory of special functions, and so on. However, it is in the field of number theory $[8,80,107]$ that they are investigated in greater depth and where their fundamental studies and main theoretical advances are concentrated. The

${ }^{*}$ This work is a partial result of my postdoctoral research carried out in the Postgraduate Program in Music at Federal University of Rio de Janeiro (UFRJ), under the supervision of Professor Dr. Liduino Pitombeira, to whom I am very grateful for all the support and collaboration over the past two years. I also thank Professors Dr. Pauxy Gentil-Nunes and Dr. Carlos Almada, for the enriching conversations and for their dedication to the MusMat research group, making it a welcoming and enthusiastic environment for scientific and musical development. And finally, I thank the reviewers for their valuable suggestions.

Received: June 11th, 2020

Approved: July 9th, 2020

${ }^{1}$ Throughout this work, partitions refer mostly, but not exclusively, to integer partitions. For definitions, see Section II. 
simple notion of dividing an object into sub-objects makes partitions find use in the most varied fields of knowledge, from, for example, non-parametric statistics to particle physics [9, pp. xv-xvi].

The use of partitions in music dates back to the incursion of mathematical combinatorics into music theory in the 17th century [94,127], and comprise a wide range of applications with great potential for both musical composition and analysis. Among some of the works that associate partitions and music in a more explicit way, we highlight the early studies of twelve-tone partitioning, in particular the source set approaches of Babbitt [13, 14, 15], Perle [129, 130, 131] and Martino [108], in addition to other studies in combinatoriality by Forte [56], Howe [85] and Gamer [65]. In the same direction, we also mention the works of Wintle [175], Bazelow and Brickle [20], Morris and Starr [117, 124, 161, 162, 163], Haimo and Johnson [77], and the further partitional or mosaic approaches of Mead [110, 111], Kurth [97, 98, 99, 100], Morris and Alegant $[2,3,4,5,6,122,123]$. Morris still uses partitions to shape some of his compositional designs, especially the Design VI [118, pp. 265-270]. Although this is an extensive list, even chronologically speaking, it is worth noting that most of these works employ partitions of the aggregate, or rather set partitions, ${ }^{2}$ almost exclusively. Other relatively recent works present varied musical applications for partitions with a more mathematical approach. ${ }^{3}$

In Brazil, a seminal work relating partitions to musical texture is the partitional analysis, attributed to Gentil-Nunes [66], which consists of an original approach to musical composition and analysis based on a convergence between the theory of partitions and the textural analysis proposed by Berry [26]. Through an exhaustive taxonomy for the texture parameter, it offers a topological and metric mapping of textural configurations, and presents formal structures that can be applied to various fields of texture. It also includes some original concepts, such as the agglomeration and dispersion indices, the partitional operators, as well as the software Parsemat ${ }^{\circledR}$ and its graphical tools-the indexogram and partitiogram.

In the wake of partitional analysis, many other works have been carried out, ${ }^{4}$ especially within the MusMat research group, ${ }^{5}$ associating partitions with varied musical parameters or aspects such as rhythm, timbre, melody, contours, gestures, events, etc. Moreover, not only new tools have been developed, but the theory itself has been considerably expanded, mainly by the recent works of Gentil-Nunes [67, 68] and Sousa [157, 158, 159].

Given the strong influence of Berry's textural approach, inherent to the very conception of partitional analysis [69], it is natural that most of these works are concerned with musical texture and its elements. Therefore, although Berry addresses harmony in the first chapter of his book (tonality) and even in the second (texture)-precisely when discussing the concepts of density and dissonance [26, pp. 209-213], essentially harmonic (vertical) aspects, or more specifically, aspects related to the musical organization and structuring of pitches have not yet been deeply explored in the light of partitional analysis.

In this regard, as Gentil-Nunes [67, p. 107] points out, "each partitioning has its own idiosyncrasy and has to be evaluated from scratch in this respect, since each handled material has its own nature." Bearing that in mind, we propose a way of conceiving harmony and harmonic relations through the partitioning of pitch spaces. As we shall see, this comprehensive harmonic conception, which we call partitional harmony, relates the theory of partitions to several fields of post-tonal

\footnotetext{
${ }^{2}$ Set partitions concern the ways in which a set of $n$ elements can be split up into a set of disjoint subsets [9, p. 214]. A partition of a set is "a collection of disjoint sets whose union is the given set" [86]. For example, the set $\{1,2,3\}$ has 5 set partitions: $\{1,2,3\} ;\{1,2\},\{3\} ;\{1,3\},\{2\} ;\{2,3\},\{1\} ;\{1\},\{2\},\{3\}$. An alternative representation may be: $123,12|3,13| 2$, $1|23,1| 2 \mid 3$. See also [106].

${ }^{3}$ See $[43,51,61,62,63,87,91,105,109,169]$.

${ }^{4}$ Publications related to partitional analysis are available on Gentil-Nunes' personal website: https://pauxy.net/ partitional-analysis-publications.

${ }^{5}$ The list of works published by the group is available at: https://musmat.org/publicacoes-papers.
} 
music theory, especially pitch-class set theory, but also transformational theory and diatonic set theory, showing great potential for integration with partitional analysis itself, in addition to other musical and even mathematical theories. Last but not least, such a partitional approach to harmony allows us to establish harmonic directionality and functionality in post-tonal musical contexts, paving the way for the development of a post-tonal system, if we can speak of such a thing, and finally-in a broader sense-a post-tonal harmony.

\section{The Theory of PARtitions}

According to Andrews [8, p. 149], "the theory of partitions is an area of additive number theory, a subject concerning the representation of integers as sums of other integers." By his definition, a partition of a positive integer $n$ is a representation of $n$ as a sum of positive integers, called summands or parts of the partition, the order of which is irrelevant. More formally [9, p. 1], a partition of a positive integer $n$ is a finite non-increasing sequence of positive integers $\lambda=\left(\lambda_{1}, \lambda_{2}, \ldots, \lambda_{k}\right)$, such that $\sum_{i=1}^{k} \lambda_{i}=n$. Each $\lambda_{i}$ corresponds to a part of the partition and if $\lambda$ is a partition of $n$, then we write either $\lambda \vdash n$ or $|\lambda|=n$. We call $\lambda$ a $k$-partition if $\lambda$ has $k$ parts, and the number of parts of $\lambda$ is also called the length of $\lambda$, being denoted by $\ell(\lambda)$ [160, p. 58].

The number of distinct partitions of a positive integer $n$ is given by $p(n)$, called the partition function. So, for example, $p(4)=5$, as there are altogether 5 different ways to write the number 4 as a sum of positive integers: $4=3+1=2+2=2+1+1=1+1+1+1$. It is clear that the partitions of $n$ correspond to the set of solutions $\left(j_{1}, j_{2}, \ldots, j_{n}\right)$ of the Diophantine equation $1 j_{1}+2 j_{2}+\ldots+n j_{n}=n$ [173]. Therefore, in our example, the partitions $(4),(3,1),(2,2),(2,1,1)$, $(1,1,1,1)$ correspond, respectively, to the solutions $\left(j_{1}, j_{2}, j_{3}, j_{4}\right)=(0,0,0,1),(1,0,1,0),(0,2,0,0)$, $(2,1,0,0),(4,0,0,0)$ of the equation $1 j_{1}+2 j_{2}+3 j_{3}+4 j_{4}=4$. By definition, $p(n)=0$, when $n$ is negative, and by convention, $p(0)=1$, referring to the empty partition (with no parts). Table 1 shows the values of $p(n)$ for each corresponding $n$.

Table 1: Values of $p(n)$, for $n=\{0,1, \ldots, 12\}$.

\begin{tabular}{c|ccccccccccccc}
$n$ & 0 & 1 & 2 & 3 & 4 & 5 & 6 & 7 & 8 & 9 & 10 & 11 & 12 \\
\hline$p(n)$ & 1 & 1 & 2 & 3 & 5 & 7 & 11 & 15 & 22 & 30 & 42 & 56 & 77
\end{tabular}

The partition function, despite its conceptual simplicity, is not at all obvious or trivial. As $n$ grows, the number of partitions increases quite rapidly, making the calculation more and more difficult and complex. For example, $p(50)=204226, p(100)=190569292$ and $p(200)=$ 3972999029388. Not surprisingly, the study of this function has been an object of interest to notable mathematicians since the mid-18th century, playing a central role in the development of number theory. Among some of the most relevant works, we can highlight the generating function for $p(n)$, developed by Euler [53], the asymptotic formula by Hardy and Ramanujan [79], perfected two decades later by Rademacher [137, 138], and-more recently-the algebraic formula by Bruinier and Ono [34], which expresses $p(n)$ as a finite sum of algebraic numbers, in addition to the discovery of the "fractal behavior" of partitions by Folsom, Kent and Ono [55].

While $p(n)$ comprises the set of all unrestricted partitions of $n$, other functions are limited to subsets of restricted partitions, i.e., partitions whose parts satisfy some condition. A function like $p(S, n)$, for example, denotes the number of partitions of $n$ that belong to a subset $S$ of partitions whose parts can be even, odd, distinct, prime, etc. [9, p. 2]. Other functions such as $p_{k}(n)$ and $p(j, k, n)$ denote, respectively, the number of partitions of $n$ with exactly $k$ parts and the number of partitions of $n$ into at most $k$ parts, with largest part at most $j$ [160, p. 58]. Still others may be 
constrained to even smaller subsets or establish even more specific conditions. Functions involving restricted partitions can be simply represented by the generic formula $p(n \mid$ [condition] $)[11, \mathrm{p} .6$ ] - for example, $p(n \mid$ odd parts $), p(n \mid$ distinct parts in $\{3,6,12,24, \ldots\}), p(n-r \mid$ all parts $\leq r)$, and so forth. Table 2 shows the values of $p_{k}(12)$, or $p(12 \mid k$ parts $)$, for each corresponding $k$.

Table 2: Values of $p_{k}(12)$, for $k=\{1,2, \ldots, 12\}$.

\begin{tabular}{c|cccccccccccc}
$k$ & 1 & 2 & 3 & 4 & 5 & 6 & 7 & 8 & 9 & 10 & 11 & 12 \\
\hline$p_{k}(12)$ & 1 & 6 & 12 & 15 & 13 & 11 & 7 & 5 & 3 & 2 & 1 & 1
\end{tabular}

In general, partitions are represented as arithmetic series, with terms (parts) arranged in non-increasing order. However, they can also be represented with more convenient configurations [174], depending on the context and their applications. The most common form is the standard or natural representation which simply gives the sequence of numbers in the representation-e.g., $(2,1,1)$ for the number $4=2+1+1$. The multiplicity representation instead gives the number of times each number occurs together with that number-e.g., $(2,1),(1,2)$ for $4=2 \cdot 1+1 \cdot 2$. Besides that, the parts may also be grouped into sequences, lists, tuples or vectors, may or may not be enclosed in brackets, be separated by commas, periods or spaces, or even have no separators. Their order can be increasing or non-increasing, decreasing or non-decreasing, lexicographic or anti-lexicographic, etc. Furthermore, partitions can be written even more concisely, through the frequency representation ("power notation"), in which the number of occurrences of each part is denoted by a corresponding exponent. ${ }^{6}$ Table 3 presents some possibilities of representing the partition $7+5+5+3+2+2+2+1+1+1+1$ of 30 .

Table 3: Possible representations of $7+5+5+3+2+2+2+1+1+1+1$.

\begin{tabular}{|c|c|}
\hline$(7,5,5,3,2,2,2,1,1,1,1)$ & $(1,1,1,1,2,2,2,3,5,5,7)$ \\
\hline$(75532221111)$ & $(11112223557)$ \\
\hline$(75532221111)$ & $(11112223557)$ \\
\hline$\left(7^{1} 5^{2} 3^{1} 2^{3} 1^{4}\right)$ & $\left(1^{4} 2^{3} 3^{1} 5^{2} 7^{1}\right)$ \\
\hline$\left(75^{2} 32^{3} 1^{4}\right)$ & $\left(1^{4} 2^{3} 35^{2} 7\right)$ \\
\hline
\end{tabular}

Apart from such numerical configurations, the partitions can also be represented graphically, through the Ferrers diagram or the Young diagram, in which the parts correspond, respectively, to dots or squares distributed horizontally and vertically in the plane, according to their size and multiplicity. As an example, the graphical representations of the partition $4+3+3+2+1$ of 13 , in the respective diagrams, are shown in Figure 1.

Graphical representations are often useful for illustrating or performing transformations in partitions and also for demonstrating certain properties called partition identities [1]. These identities consist of correspondence or congruence relations between restricted partitions. One of the simplest identity can be obtained through conjugation, a transformation of the partition operated in the Ferrers diagram, in such a way that the rows of the first diagram become the columns of the second (and vice versa), resulting in a partition with the greatest part equal to the number of parts of the original partition, i.e., $p(n \mid k$ parts $)=p(n \mid$ greatest part is $k)$ [11, p. 17].

We can notice in Figure 2 that the transformation by conjugation corresponds to the rotation of the original diagram around its diagonal axis (highlighted by the darker dots). In this way, the parti-

${ }^{6}$ When a part occurs only once its exponent may be omitted. 


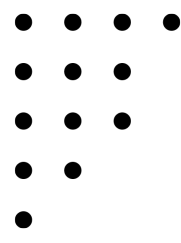

(a) Ferrers diagram

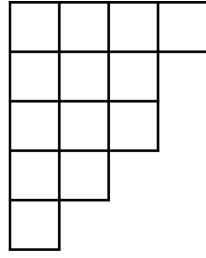

(b) Young diagram

Figure 1: Graphical representations of $\left(43^{2} 21\right)$.

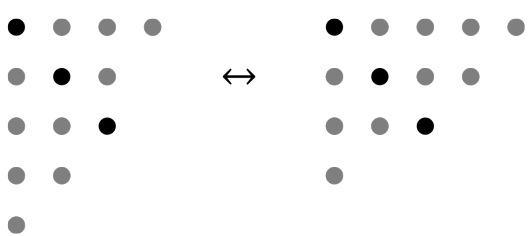

Figure 2: Conjugation between partitions $\left(43^{2} 21\right)$ and (5431).

tions $\left(43^{2} 21\right)$ and (5431) map to each other and are therefore called conjugate partitions. ${ }^{7}$ It is worth pointing out that the sum of the parts of the conjugated partitions is always the same, which means that they are invariably partitions of the same positive integer. Finally, from other conjugation properties, we can come to new partition identities [11, pp. 17-18]-for example, $p(n \mid \leq k$ parts $)=$ $p(n \mid$ all parts $\leq k), p(n \mid$ distinct parts $)=p(n \mid$ parts of every size from 1 to the largest part $)$, $p(n \mid$ self-conjugate $)=p(n \mid$ distinct odd parts $)$, and so on.

Many other identities can be obtained in a similar way or through more sophisticated mathematical methods. Moreover, other graphic representations, such as Young's lattice, Young tableaux, Hasse diagram, Durfee square, etc., are equally useful and have numerous applications. However, we limit ourselves here to just mentioning them, since the description of their attributes would go beyond the scope of this preliminary work.

As we have seen, the order of the parts of a partition is irrelevant, which characterizes an unordered partition. On the other hand, when the order of the parts is considered, then we have what we call an ordered partition or, simply, a composition ${ }^{8}[9, \mathrm{p}$. 54]. Thereby, a composition

Table 4: Values of $c(n)$, for $n=\{0,1, \ldots, 12\}$.

\begin{tabular}{c|ccccccccccccc}
$n$ & 0 & 1 & 2 & 3 & 4 & 5 & 6 & 7 & 8 & 9 & 10 & 11 & 12 \\
\hline$c(n)$ & 1 & 1 & 2 & 4 & 8 & 16 & 32 & 64 & 128 & 256 & 512 & 1024 & 2048
\end{tabular}

Table 5: Values of $c_{k}(12)$, for $k=\{1,2, \ldots, 12\}$.

\begin{tabular}{c|cccccccccccc}
$k$ & 1 & 2 & 3 & 4 & 5 & 6 & 7 & 8 & 9 & 10 & 11 & 12 \\
\hline$c_{k}(12)$ & 1 & 11 & 55 & 165 & 330 & 462 & 462 & 330 & 165 & 55 & 11 & 1
\end{tabular}

\footnotetext{
${ }^{7}$ A partition that is its own conjugate is called self-conjugate-e.g., $\left(43^{2} 1\right)$.

${ }^{8}$ Despite the term composition already has a specific meaning in music, we use it here since it is well established in mathematics and for its practical advantages. Nevertheless, the disambiguation between musical composition and integer composition should be easily inferred from the context in which each term is used.
} 
of $n$ can be thought of as an expression of $n$ as an ordered sum of integers [160, p. 17]. More precisely, a composition of $n$ is a finite (ordered) sequence of positive integers $\alpha=\left\langle\alpha_{1}, \alpha_{2}, \ldots, \alpha_{k}\right\rangle,{ }^{9}$ such that $\sum_{i=1}^{k} \alpha_{i}=n$. For example, for $n=4$, besides the 5 partitions: (4), (31), $\left(2^{2}\right),\left(21^{2}\right)$, $\left(1^{4}\right)$; there are 8 distinct compositions: $\langle 4\rangle,\langle 31\rangle,\langle 13\rangle,\langle 22\rangle,\langle 211\rangle,\langle 121\rangle,\langle 112\rangle,\langle 1111\rangle$. The number of all compositions of a positive integer $n$ is given by the composition function $c(n)=2^{n-1}$, and the number of compositions of $n$ with $k$ parts ${ }^{10}$ is given by $c_{k}(n)=\left(\begin{array}{c}n-1 \\ k-1\end{array}\right)=\frac{(n-1) !}{(k-1) !(n-k) !}$. Likewise, $c(n)=0$, when $n$ is negative, and $c(0)=1$, the empty composition (with no parts). If a composition $\alpha$ has $k$ parts, then we call $\alpha$ a $k$-composition. We can also express functions involving restricted compositions using the generic formula $c(n \mid$ [condition]). Tables 4 and 5 show, respectively, the values of $c(n)$ and $c_{k}(12)$, or $c(12 \mid k$ parts), for each corresponding $n$ and $k$.

As Andrews points out [9, p. 55], compositions may also be represented graphically. To the composition $\left\langle a_{1}, a_{2}, \ldots, a_{k}\right\rangle$ of $n$ we can associate $k$ segments of the interval $[0, n]$, so that the first segment is of length $a_{1}$, the second of length $a_{2}$, and so on. As an example, the composition $\langle 32312\rangle$ of 11 can be represented as showed in Figure 3.

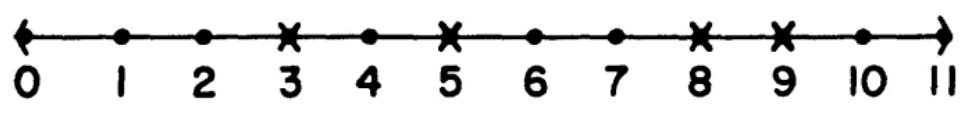

Figure 3: Graphical representation of the composition 〈32312〉. Reproduced from Andrews [9, p. 55]. Copyright 1984 by Cambridge University Press. Reproduced with permission of Cambridge University Press through PLSclear.

It is important to observe that many aspects of partitions naturally extend to compositions, which also present interesting properties and identities. ${ }^{11}$ In addition, due to their flexibility and versatility, both find applications in different segments of discrete and combinatorial mathematics, such as set theory, group theory, graph theory, modern algebra, etc. ${ }^{12}$ By way of illustration, we mention here the methods used in the combinatorics of pattern avoidance and pattern enumeration in set partitions [106], and the close connection between subsets of a set and compositions of a non-negative integer in enumerative combinatorics [160].

Before we close this brief introduction to the theory of partitions, it is useful to introduce the concept of multipartition, which has only recently been studied for its own intrinsic interest [10]. By Fayers definition [54, p. 115], a multipartition of $n$ with $k$ components is a $k$-tuple $\lambda=\left(\lambda^{(1)}, \lambda^{(2)}, \ldots, \lambda^{(k)}\right)$ of partitions, such that $\left|\lambda^{(1)}\right|+\left|\lambda^{(2)}\right| \cdots+\left|\lambda^{(k)}\right|=n$. If $k$ is understood, we shall just call this a multipartition of $n$. As with partitions, 0 (zero) has a unique multipartitionthe empty one, and if $\lambda$ is a multipartition of $n$, then we write $\lambda \vdash n$ or $|\lambda|=n$. For example, $\left((431),\left(42^{3}\right),(321)\right)$ is a multipartition of 24 . If the order of the parts is relevant, then we can extend this definition to the compositions and arrive at the analogous concept of multicomposition. So, $\left\langle\langle 143\rangle,\left\langle 2^{2} 42\right\rangle,\langle 132\rangle\right\rangle$ is a multicomposition of 24 .

Having seen so far some of the elementary properties of integer partitions, let's check below how they can be useful for the formulation of a harmonic conception through the partitioning of pitch spaces.

\footnotetext{
${ }^{9}$ In this work, we differentiate partitions from compositions by using round ( ) and angle \langle\rangle brackets, respectively.

${ }^{10} \mathrm{~A}$ composition whose parts may be equal to 0 (zero) is called a weak composition. The number of all weak compositions of $n$ is obviously infinite, but the number of weak compositions of $n$ with $k$ parts is given by $c_{k}(n)=\left(\begin{array}{c}n+k-1 \\ k-1\end{array}\right)=\frac{(n+k-1) !}{n !(k-1) !}$.

${ }^{11}$ See, for example, $[23,75,76,95,113,125,126]$.

${ }^{12}$ For an introduction to many of these topics, see [74].
} 


\section{The Partitioning of Pitch Spaces}

In acoustics, pitch ${ }^{13}$ characterizes one of the perceptual attributes of sound ${ }^{14}$ and is defined as "that aspect of auditory sensation in terms of which sounds may be ordered on a scale extending from low to high, such as a musical scale" [24, p. 397]. It is a subjective quantity despite being related to the sound frequency, which in turn is a definite physical quantity that can be measured on physical instruments without any reference to the ear. Thus, if frequency is a physical measure of vibrations or cycles per second-given in hertz $(\mathrm{Hz})$, pitch is the corresponding perceptual experience of frequency [105, p. 13]. In other words, pitch is "our subjective evaluation of sound frequency" [17, p. 112], or "the intersubjective correlate of frequency" [118, p. 23].

Generally speaking, for any given frequency there will be perceived a certain pitch, i.e., low frequencies correspond to low pitches, and conversely. In the case of pure tones, ${ }^{15}$ pitch is directly related to the frequency of the sound wave, and in the case of more complex sounds, it is determined by what the ear judges to be the most fundamental wave frequency of the sound [82]. However, this correspondence is not exact, since pitch is also determined by other factors such as frequency range ${ }^{16}$ and region, sound complexity, duration, intensity, and even by hearing disorders [17, p. 112]. The perception may be different depending on the situations, so that a specific frequency will not always have the same pitch. But for practical and musical purposes, given that those factors have little effect on the pitch of musical tones, ${ }^{17}$ we may disregard them and use the two terms frequency and pitch as essentially synonymous when referring to musical sounds of definite pitch. ${ }^{18}$

We may also think of these pitched sounds, or rather this pitch domain [141], as a generic musical space $^{19}$ of pitches, i.e., a generic pitch space. According to Harley [81, pp. 90-107], the recognition of the spatial quality of pitch relationships is common to many theories of musical space. These relationships are spatial in an abstract sense and may be formalized and generalized through mathematical notions of space (e.g., continuum, metric space, vector space, and so on). Thus, the vertical dimension of music can be described as a system of relationships that comprises two aspects of pitch-one which changes monotonically with frequency (as an approximate logarithmic function of frequency $[12,16,133]$ ) and one rotating in a cycle of octave repetitions (octave equivalence). In modern psychoacoustic terminology, this distinction is expressed respectively

\footnotetext{
${ }^{13}$ According to the current American National Standard on Acoustical Terminology (ANSI/ASA S1.1-2013) [7], pitch is "that attribute of auditory sensation by which sounds are ordered on the scale used for melody in music." The pitch of a sound "may be described by the frequency of that simple tone having a specified sound pressure level that is judged by listeners to produce the same pitch." In addition, we can consider as practical dimensions for pitch: "(1) the perceptual dimension of pitch height, which defines the position of the tone along a scale from low to high, normally monotonic with the physical dimension of frequency; (2) the circular dimension of pitch class, which defines the position of the tone within the octave."

${ }^{14}$ The others are loudness, timbre, duration, and spatial perception.

${ }^{15} \mathrm{~A}$ tone is a sound wave capable of exciting an auditory sensation having pitch. A pure tone, or simple tone, is a sound wave, the instantaneous sound pressure of which is a sinusoidal function of time (a sine wave) [7].

${ }^{16}$ The frequency range of human hearing is between approximately 20 to $20000 \mathrm{~Hz}$, varying from person to person according to age and gender. Pitch discrimination is very poor and drops off near the lower limit (below about $30 \mathrm{~Hz}$ ) and also at high frequencies (above about $5000 \mathrm{~Hz}$ ) [105, p. 159], being practically nonexistent above about $10000 \mathrm{~Hz}$ [17, p. $111]$.

${ }^{17}$ A musical tone is a kind of (periodic) sound produced by most of our musical instruments, which lasts long enough and is steady enough for the ear to ascribe to it three characteristics-loudness, quality (timbre), and pitch [17, p. 94]

${ }^{18}$ The frequency range of pitched musical sounds, i.e., the useful range of fundamental frequencies of tones produced by musical instruments is considerably narrower than that of audible frequencies, being approximately 27 to $4200 \mathrm{~Hz}-$ slightly wider than the piano's range. The high-frequency region above that accommodates the harmonics of the high tones and other sounds of indefinite pitch (e.g., sounds produced by unpitched percussion instruments, noises such as bow scrapings, clinking of keys, and so forth) [17, p. 111].

${ }^{19}$ We refer here to the term as it is broadly used by Lewin [104]. For a thorough review about music and space, see [81].
} 
by the concepts of pitch height (linear dimension) and pitch chroma (cyclic dimension). ${ }^{20}$ Both dimensions can be combined in a geometric model of a cylindrical spiral, generating a helical representation of pitch known as the pitch helix. ${ }^{21}$ Figure 4 shows Shepard's pitch helix, in which the rectilinear scale of pitch is deformed into a simple regular helix having one complete turn per octave (height), and collapsed into a circle where there is complete perceptual identity of all tones in the octave relation (chroma) [154, p. 352]. This duality between the rectilinearity and circularity of pitch underlies the disambiguation of pitches and pitch classes, ${ }^{22}$ as well as the conceptualization of linear and cyclic (modular) pitch spaces, namely and respectively, pitch spaces and pitch-class spaces.

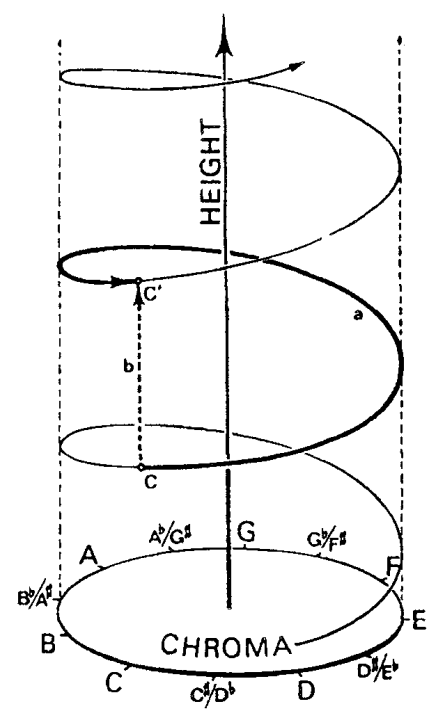

Figure 4: The pitch helix. Reproduced from Shepard [153, p. 105]. Copyright 1965 by the Board of Trustees of the Leland Stanford Jr. University. Reproduced with permission of Stanford University Press.

At this point, we ought to dwell on the following question: how do we select out of the whole range of pitches those to be used musically, or rather, how do we construct useful musical scales, or even musical systems, ${ }^{23}$ out of the continuum of available pitches? Since, by the fairly universal concept of octave generalization, ${ }^{24}$ pitches separated by an octave are in some sense musically similar or equivalent (have the same chroma), in numerous cultures, musical scales are often defined by specifying the intervals ${ }^{25}$ within an octave, ${ }^{26}$ whether from a natural (physical) basis or not. Once these intervals are determined and replicated successively across each octave, the pitch continuum is then discretized into a finite number of pitches. Therefore, despite various-let's

\footnotetext{
${ }^{20}$ These concepts were originally defined by Bachem [16] as tone height and tone chroma. For related uses and further developments, see [32, 48, 49, 50, 89, 96, 101, 136, 141, 144, 151, 153, 154, 168, 171, 172].

${ }^{21}$ Other multidimensional representations are also possible, see [154].

${ }^{22}$ A pitch class is "a collection of pitches related by octave and enharmonic equivalence" [165, p. 5].

${ }^{23}$ For a deep survey on the "domain of musical systems," see [29, 30].

${ }^{24}$ For an in-depth discussion about musical intervals, scales, and tuning systems in different cultures from a perceptual perspective, see [36].

${ }^{25} \mathrm{An}$ interval is "the spacing in pitch [perceptually] or frequency [physically], as indicated by context, between two tones." The frequency spacing is "expressed by the ratio of the frequencies or by a specified logarithm of this ratio" [7]. See also [133].

${ }^{26}$ Although less common, there are also musical systems based on intervals of equivalence (modular intervals) other than the octave-e.g., the naturale, durum, and molle hexachords of medieval solmization ("Guidonian") system, or any arbitrary system that divides other intervals, or that deliberately ignores the acoustic similarity of the octave.
} 
say-non-structural pitch glides (glissandi, portamenti, trills, and other ornamentation), most musical systems are predicated on discrete intervals, so that practical music is limited to a relatively small set of discrete pitch relationships.

It may seem odd or counter-intuitive, but in such musical systems pitches are actually determined by intervals, and not the other way around. Furthermore, the sonic identity or profile of a musical system is determined not so much by its proper pitches (unless one has absolute pitch) as by the intervals between them. In this sense, intervals precede pitches. This paradoxical aphorism-particularly true in Western music ${ }^{27}$-not only is the cornerstone of our present harmonic conception, but also underpins many theoretical works on post-tonal music which deal, to some extent, with pitch relationships through an intervallic approach. ${ }^{28}$

In fact, particularly with regard to harmony, pitches are not as musically relevant as intervals. Most of us rarely treat individual pitches as auditory units or tie particular behaviors to them, instead, our pitch perception is "relationally determined", and that is because pitch is a "morphophoric" (form-bearing) medium, in which the same musical patterns or configurations may have different locations and still preserve their perceived structural identities [12, pp. 147-148]. Then we are generally more responsive to the relations and ratios between pitches than to those pitches themselves [154, p. 344]. In other words, "the quality of a musical pitch depends critically on its relations to other musical pitches" [96, p. 112], and such relations, or "configural properties," are precisely the intervals. This is quite clear, for example, when a song is transposed, or when an orchestra is tuned to a pitch other than the standard $A=440 \mathrm{~Hz}$, and yet the original musical relationships-and the music itself-remain essentially the same. This is also true for a music student who learns the interval patterns of each type of scale/chord (major, minor, etc.) before building them on any tonic/root. Hence, intervals are determinant not only for the way we perceive and recognize music, but also for how we understand and conceive its most fundamental and structural relationships. ${ }^{29}$

As stated above, intervals play a crucial role in the construction of most musical systems. In a similar fashion, since "the basic notion of interval, i.e., distance, is crucial for the musical structuring of pitch, and the mathematical structuring of space (metric space)" [81, p. 97], they are also essential for defining pitch spaces. Roughly speaking, a pitch space is basically what the term implies-“a space of pitches" [118, p. 346]. The concept of space here, though rather vague, should be understood mostly in the mathematical sense of the term, namely as an abstract space. ${ }^{30}$ Thus, a pitch space corresponds to "a theoretical model setting forth 'distance' relationships between pitches" [116]. Depending on their complexity, different pitch spaces correspond to varied models, often mathematical, ${ }^{31}$ such as geometric shapes (line, circle, helix, torus, etc.), in addition to graphs, groups, grids, and lattices (Tonnetz), or even more abstract formulations like equations, ordered pairs, multidimensional vectors, and so forth. In general, pitches with equivalent musical

\footnotetext{
${ }^{27}$ Most Western musical systems, like Pythagorean tuning, Just intonation, Meantone temperament, Well and Equal temperaments, among others, are interval-based (i.e., frequency-ratio-based) systems. For further explanation on this and comparisons between different systems, see [17, 19, 21, 36, 105, 133, 152, 170].

${ }^{28}$ See $[18,38,39,40,41,42,45,57,64,78,118,119,142,155,156]$. Some of these works are discussed at length and in historical perspective in [150], see also [25].

${ }^{29}$ Notwithstanding this logical deduction, Krumhansl's experiment indicates that "all intervals of equal size are not perceived as equal when the tones are heard in tonal contexts. Instead, the degree to which listeners judge tones to be related depends on their functions in the key" [96, p. 120].

${ }^{30} \mathrm{An}$ abstract space is "a formal mathematical system consisting of undefined objects and axioms of a geometric nature" (e.g., Euclidean spaces, metric spaces, topological spaces, vector spaces, etc.). On the other hand, a mathematical system is (1) "a set of quantities having some common property" (e.g., the system of even integers, the system of lines passing through the origin, etc.), or (2) "a set of principles concerned with a central objective" (e.g., a coordinate system, a system notation, etc.) [86].

${ }^{31} \mathrm{~A}$ mathematical model is "a mathematical construct designed to study a particular real-world system or phenomenon" [70, p. 60], or basically, a description or representation of a system in mathematical terms (concepts and language).
} 
relationships are equally spaced within those models, and closely related pitches are placed next to one another (and conversely). Also, octave-related pitches may or may not be distinguished, which characterizes a pitch or a pitch-class space, respectively.

If, on the one hand, pitch spaces usually correspond to mathematical models, on the other, considering contemporary approaches to perception, they are not entirely mathematical. Recent cognitive studies show that there is considerable evidence on the phenomenical aspects of pitch spaces in musical perception. ${ }^{32}$ Still, since they are somehow models of musical systems (pitch systems in our particular case), ${ }^{33}$ they can be somewhat classified by the same criteria common to mathematical modelling and systems theory literature. ${ }^{34}$ Therefore, pitch spaces can be concrete, representational, or abstract at first, ${ }^{35}$ but also natural vs. artificial (designed), linear vs. non-linear, static vs. dynamic, implicit vs. explicit, continuous vs. discrete, deterministic vs. probabilistic (stochastic), mechanistic vs. empirical (statistical), open vs. closed, and so on. We will not go further here on all of those properties and their definitions, since they are well known in the specific literature and, to a certain degree, self-explanatory. For the moment, it is sufficient to notice that some of them make more sense and are more relevant to pitch spaces than others. Figure 5 shows a preliminary classification of pitch spaces in mathematical terms, in the form of a schematic diagram, partly based on those properties which we judge to be the most significant for our present purposes, and partly in other geometric and algebraic concepts. ${ }^{36}$

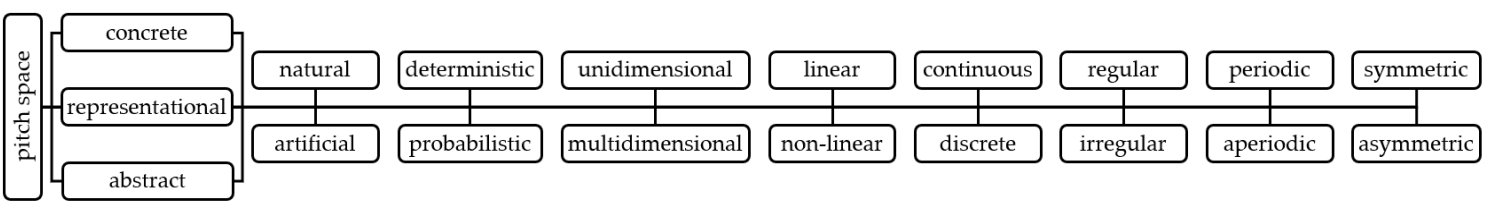

Figure 5: Classification of pitch spaces in mathematical terms.

Different approaches and taxonomies from various authors use some of those among other original criteria to define and classify not only pitch spaces, but also musical spaces in general, including spaces of chords, scales, harmonic progressions, tonal regions and keys, rhythms, timbres, and so on. ${ }^{37}$ Morris [118], for example, defines five types of pitch spaces: the contour space (c-space), which corresponds to the pitch continuum, where the sizes of intervals between the pitches are undefined or ignored; the linear pitch space ( $p$-space) and unequal space (u-space), which have, respectively, equal and unequal intervals between their successive adjacent pitches; and, finally, the cyclic pitch-class space ( $p c$-space) and modular space (m-space), which are the collapsed pitch-class versions of the previous two, respectively. Figure 6 presents Gentil-Nunes' graphical representations of those pitch spaces.

Naturally, as we can see, the pitch continuum is the most fundamental pitch space. In brief,

\footnotetext{
${ }^{32}$ For an interesting discussion about the paradoxes of pitch spaces involving mathematical models of musical space and embodied models of musical perception, see [33].

${ }^{33}$ System here should be understood in the light of the General System Theory (GST), i.e., as "a complex of interacting elements" [27, p. 55], or rather, as "a set of elements or parts that is coherently organized and interconnected in a pattern or structure that produces a characteristic set of behaviors" [112, p. 188]. Klir [93, pp. 4-5] defines a system as "a set or arrangement of things so related or connected as to form a unity or organic whole", formalizing this common-sense definition through the equation $S=(T, R)$, where $S, T, R$, denote, respectively, a system, a set of things distinguished within $S$, and a relation (or, possibly, a set of relations) defined on $T$.

${ }^{34}$ For an introductory reference on both of these topics, see [22, 27, 47, 52, 70, 90, 93, 112, 114, 149].

${ }^{35}$ Although common in the referred literature, these terms and the concepts behind them were borrowed from the Concrete-Representational-Abstract (CRA) educational approach [84].

${ }^{36}$ Further details on this classification will be provided on another occasion.

${ }^{37}$ We highlight here $[31,46,88,103,104,109,118,166,167,176]$. For others, see again $[81,96]$.
} 
by partitioning it we derive the discrete pitch spaces, and by collapsing these latter we obtain the discrete pitch-class spaces. ${ }^{38}$ Continuous pitch spaces are useful in many contexts, however, for obvious reasons, we can only infer definite harmonic relationships from the discrete ones. The harmonic properties of a discrete pitch space depend essentially on its intervallic structure, which, again, may be evenly or unevenly constructed, i.e., with regular or irregular intervals (or interval patterns). Different structures imply different results for transformational operations on musical objects. For example, the transposition or inversion of a musical motif performed within a diatonic space will be different from that within a chromatic space, precisely because the "step distances" [102, 103]-the distances in diatonic or chromatic adjacent steps ${ }^{39}$-are not the same in both spaces. In this regard, each pitch space consists of a unique musical universe with its own sonic characteristics and harmonic peculiarities. Pitch spaces with irregular or asymmetric interval environments tend to determine tonal centers and confer a unique status on each pitch, since every one has a unique relation to the others in its own characteristic way. Such a framework gives rise, for example, to the typical dynamisms of tonal music (motion and rest, tension and resolution, etc.). Conversely, regular and symmetric pitch spaces tend to confer the same status on all pitches, weakening the sense of musical centricity and harmonic motion.

Often, for practical or theoretical musical reasons, we may perceive or think of pitch spaces as homogeneous spaces abstracted from their interval configuration, i.e., without distinguishing the actual distances between their adjacent pitches. For example, the successive steps of a diatonic scale (the scale degrees) may be perceived as in some sense equal, and indeed they are notated that way ( $\hat{1}, \hat{2}, \hat{3}$, etc., for tonic, supertonic, mediant, and so on), despite the asymmetric interval construction of the scale. In this sense, the notion of step distances within discrete pitch spaces presupposes, or at least suggests, that the successive pitches in those spaces are to some extent

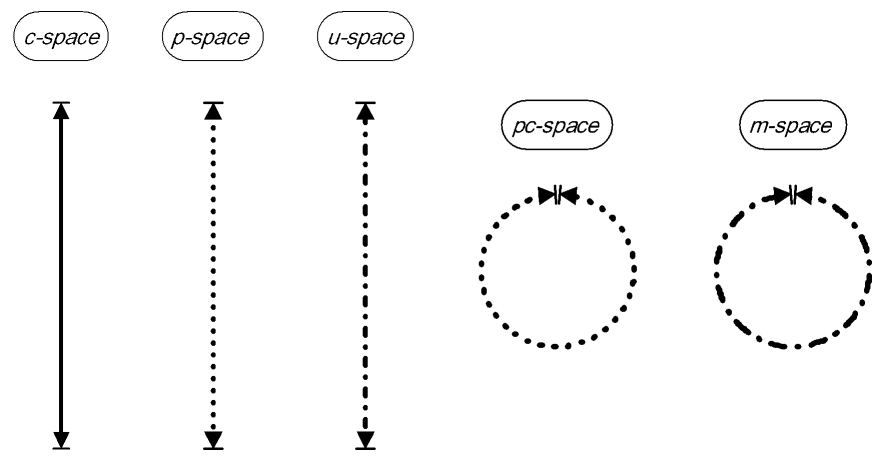

Figure 6: Graphical representations of Morris' pitch spaces. Reproduced from Gentil-Nunes [66, p. 28]. Copyright 2009 by Gentil-Nunes. Reproduced with permission of the author.

\footnotetext{
${ }^{38} \mathrm{~A}$ pitch space may also be generated from another pitch space. In addition, "certain subsets of elements taken from an equal-interval pitch space can produce a pitch space of uneven intervals" [118]. E.g., a diatonic scale drawn from a chromatic scale, the black keys of a piano keyboard, etc.

${ }^{39}$ In diatonic set theory [44], this distinction is usually made through the concepts of generic interval and specific interval, respectively. Other equivalent terms are diatonic length (dlen) and chromatic length (clen) [43], diatonic distance and chromatic distance $[146,147,148], d$ distance and $c$ distance [88], and so forth.
} 
categorically perceived ${ }^{40}$ as functionally regular, ${ }^{41}$ with the eventual interval distances between them being disregarded. According to Shepard [154, p. 373], once the pitches are "categorically mapped into the discrete nodes of an internal representation that is functionally regular, it is the structural properties inherent in that regular representation that are important." Therefore, regardless of whether a given discrete pitch space is evenly or unevenly constructed, we may conceive of it (or part of it, if multidimensional) as what we call here a categorical space, i.e., a simple directed graph ${ }^{42}$ which represents its most fundamental structure, homogenizing any irregular interval spacing, so that the vertices corresponding to the successive pitches or pitch classes are equally spaced. We can then define two types of categorical spaces, the categorical pitch space (linear) and the categorical pitch-class space (cyclic), as follows.

Def. 3.1. Categorical pitch space (cp-space). Let $V=\left\{v_{1}, v_{2}, \ldots, v_{n}\right\}$ be a set of $n$ pitches from a pitch space, arranged from low to high and labeled successively with consecutive integers, a categorical pitch space (cp-space) is a directed graph $G=(V, E)$, of order $|V|=n$ and size $|E|=n-1$, with $E=\left\{\left(v_{1}, v_{2}\right),\left(v_{2}, v_{3}\right), \ldots,\left(v_{n-1}, v_{n}\right)\right\}$.

Def. 3.2. Categorical pitch-class space (cpc-space). Let $V=\left\{v_{1}, v_{2}, \ldots, v_{n}\right\}$ be a set of $n$ pitch classes from a pitch-class space, labeled successively from 0 to $n-1$, a categorical pitch-class space (cpc-space) is a directed graph $G=(V, E)$, of order $|V|=n$ and size $|E|=n$, with $E=\left\{\left(v_{1}, v_{2}\right),\left(v_{2}, v_{3}\right), \ldots,\left(v_{n-1}, v_{n}\right),\left(v_{n}, v_{1}\right)\right\}$.

Inasmuch as categorical spaces are directed graphs, we may associate the edges between vertices with directed intervals between pitches or pitch classes. ${ }^{43}$ And for this we may use the concept of walk, ${ }^{44}$ so that the directed interval between two pitches or pitch classes is equal to the length ${ }^{45}$ of the corresponding walk. Accordingly, we define a categorical interval as follows.

Def. 3.3. Categorical interval (ci). Let $G=(V, E)$ be a categorical pitch or pitch-class space, a categorical interval (ci) between $x$ and $y$, with $x, y \in V$, is given by $c i_{x-y}=l$, where $l$ is the length of a $x-y$ walk in $G$.

Remark. In a categorical pitch-class space, if $l<|E|$, then the categorical interval is called simple, whereas if $l \geq|E|$, then it is called compound. ${ }^{46}$ In this sense, we can rewrite a categorical interval as $c i_{x-y}=l=i+|E| \cdot d$, where $i=(y-x) \bmod |E|, d \in \mathbb{N}$ is the dimensional factor, $d=0$ if the

\footnotetext{
${ }^{40}$ Originally, categorical perception "refers to the concept that some stimuli can only be responded to on an absolute basis, i.e., discrimination is limited by identification" [35, p. 457]. In other words, it is "the phenomenon by which the categories possessed by an observer influences the observers' perception" [71, p. 69], or simply, "a phenomenon that occurs when signals that vary over a continuous physical scale are perceived as belonging to a small number of discrete groups" [92, $p$. 878]. However, in this work, by category "is meant a number of objects that are considered equivalent" [145, p. 5], or simply, "a set of entities that are grouped together" [72, p. 276]. Therefore, as will be defined, a categorical space is a space of those objects or entities (pitches or pitch-classes in our case), and a categorical interval is the distance between them within that respective space.

${ }^{41}$ The term functional here should not be confused with tonal or mathematical function, but understood in its broad sense, i.e., relating to how useful something is in a certain context, or relating to the way in which it works or operates in that context.

${ }^{42} \mathrm{~A}$ simple graph is a graph without loops and with at most one edge between any two vertices. A directed graph, or digraph, is a graph in which directions are assigned to the edges, being called directed edges. For an introduction to graph theory, see again [74].

${ }^{43}$ The reasoning behind this is analogous to that of Lewin's interval definition, i.e., "a directed measurement, distance, or motion" [104, p. xxix].

${ }^{44} \mathrm{~A}$ walk is an alternating sequence of vertices and edges of a graph.

${ }^{45}$ The length of a walk is the number of edges in the walk. A walk containing no edges is called trivial.

${ }^{46}$ From these conditional statements the octave is considered here not a simple but a compound interval, i.e., the octave is a compound unison (or prime). By analogy, the notion of simple and compound categorical intervals may be extended to categorical pitch spaces, insofar they correspond to unfolded categorical pitch-class spaces.
} 
categorical interval is simple, and $d \geq 1$ if it is compound. Categorical intervals are called adjacent if they correspond to adjacent walks in $G$.

Before proceeding, let's summarize and clarify a bit more the previous definitions. If a pitch or pitch-class space is itself a model (often mathematical), then a categorical space is a functionally regular representation of that model-a simple directed graph. Since the graph is directed, its edges may be associated with directed intervals. Hence, the length of a walk between two vertices corresponds to a categorical interval between two pitches or pitch classes. Here some observations are important: 1) When a pitch or pitch-class space is already equally spaced (regular) in its original representation, the corresponding categorical space (the graph) will somehow coincide with that representation. 2) Insofar as a pitch space may contain undefined pitches and may be theoretically infinite, a categorical pitch space must correspond to a part or segment of that unlimited space. 3) Walks in a categorical pitch space are always open, since it is linear (a path graph), whereas in a categorical pitch-class space they may be open or closed, since it is cyclic (a cycle graph). ${ }^{47}$ 4) In a categorical pitch-class space, a walk can be of any length, which implies that a categorical interval can also be of any size. 5) The dimensional factor of a categorical interval corresponds to the number of octaves it comprises. Figure 7 provides a visual glimpse of the previous definitions and observations.

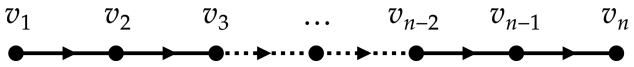

(a) Categorical pitch space (cp-space).

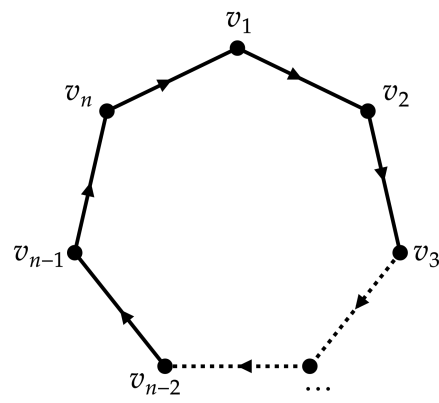

(b) Categorical pitch-class space (cpc-space).

Figure 7: Categorical spaces of pitches and pitch classes.

Now, if we look closely at the graph of Figure $7 \mathrm{a}$, we will see that it is very similar to that of Figure 3, which suggests that we may associate the categorical intervals (walk lengths) with the parts of a composition (interval segments). And indeed, we can. If a composition is basically a sequence of integers (parts) partitioning a larger integer, in a similar way, we may think of a sequence of categorical intervals partitioning a categorical pitch or pitch-class space. From this analogy, we can define what we call an interval composition.

Def. 3.4. Interval composition (ic). Let $G=(V, E)$ be a categorical pitch or pitch-class space, an interval composition (ic) of $G$ is a sequence of adjacent categorical intervals $\alpha=\left\langle\alpha_{1}, \alpha_{2}, \ldots, \alpha_{k}\right\rangle$, such that $\sum_{i=1}^{k} \alpha_{i}=|E| \cdot d$, where $d \in \mathbb{N}$ is the dimensional factor, $d=1$ if $G$ is a categorical pitch space, and $d \geq 1$ if $G$ is a categorical pitch-class space.

Remark. An interval composition is called a linear interval composition (lic) or a cyclic interval composition (cic) if $G$ is respectively a categorical pitch or pitch-class space. The elements of an

\footnotetext{
${ }^{47}$ An open walk is a walk that begins and ends at different vertices, if no edge is repeated it is called a trail, and if no vertex occurs more than once it is called a path. Contrarily, a closed walk begins and ends at the same vertex, this time, if no edge is repeated it is called a circuit, and if no vertex occurs more than once it is called a cycle.
} 
interval composition are called parts. The length of an interval composition, denoted by $\ell(\alpha)$, is the number of its parts. A subsequence of consecutive parts of an interval composition is called an interval subcomposition (isc).

And since compositions are ordered partitions, the reverse is also true, partitions are unordered compositions. Then, we can also define what we call an interval partition.

Def. 3.5. Interval partition (ip). Let $G=(V, E)$ be a categorical pitch or pitch-class space, an interval partition (ip) of $G$ is a non-decreasing sequence of categorical intervals $\lambda=\left(\lambda_{1}, \lambda_{2}, \ldots, \lambda_{k}\right)$, such that $\sum_{i=1}^{k} \lambda_{i}=|E| \cdot d$, where $d \in \mathbb{N}$ is the dimensional factor, $d=1$ if $G$ is a categorical pitch space, and $d \geq 1$ if $G$ is a categorical pitch-class space.

Remark. An interval partition is called a linear interval partition (lip) or a cyclic interval partition (cip) if $G$ is respectively a categorical pitch or pitch-class space. The elements of an interval partition are called parts. The length of an interval partition, denoted by $\ell(\lambda)$, is the number of its parts. A subsequence of parts of an interval partition is called an interval subpartition (isp).

Once again, some additional observations should be considered: 1) In a categorical pitch-class space, the dimensional factor corresponds to the number of overlapping turns around the graph. 2) Interval compositions correspond to ordered interval configurations between pitches or pitch classes, while interval partitions correspond to unordered interval configurations, being classes of interval compositions and, therefore, more abstract representations. 3) Interval partitions are arranged in a non-decreasing order for the sake of consistency with the conventional (left-compacted) models of normal form and prime form from the pitch-class set theory.

Through these concepts, which we call interval structures ${ }^{48}$ (in opposition to pitch structures), we are now able to partition the categorical spaces of pitches or pitch classes, in order to determine harmonic (musical and mathematical) relationships between those structures. But before presenting an illustrative musical application, let's define some basic operations.

\section{Basic Operations}

For the definitions and examples ${ }^{49}$ of the operations presented below, we mostly follow Morris [118] notation for pitches and pitch classes, as well as for pitch sets, pitch-class sets, and set classes, in addition to the same operators labels. None of these operations is really new, on the contrary, they are all well known in the main literature [58, 118, 128, 140, 165]. However, the use of them through interval structures, specifically interval compositions, is something relatively original.

Def. 4.1. Pitch $\left(\boldsymbol{P}_{x}\right)$. Let $\alpha=\left\langle\alpha_{1}, \alpha_{2}, \ldots, \alpha_{k}\right\rangle$ be an interval composition of a categorical pitch or pitch-class space $G=(V, E)$, the pitch operation, defined by $P_{x} \alpha$, where $x \in V$, sets $x$ as the root vertex $^{50}$ of $G$ and, consequently, the initial vertex (pitch or pitch-class) of $\alpha$.

\footnotetext{
${ }^{48}$ Despite the nuances of our concepts and the original paths we take here to reach them, they resemble many others in literature. Interval compositions are somewhat similar to Bacon's harmonies [18], Hanson's sonorities (scales) [78], Forte's interval successions [58], Chrisman's successive interval arrays [39, 40, 41, 42], Regener's chords [142], Carter's successive intervals [38], Morris' spacing, INT 1, CINT $_{1}$, and PCINT [118, 119, 120], Sorderberg's CORD and interval strings [155, 156], Straus' spacing intervals [165], and so on. On the other hand, interval partitions resemble Forte's basic interval patterns (bips) [57, 58], Jedrzejewski's partitions [87], Keith's interval sets [91], Coelho de Souza's PCORD [45], among others.

${ }^{49}$ For simplicity, all examples set out here use the twelve-tone equal temperament system (12-TET) as the basis for the categorical pitch or pitch-class spaces, which means that $|E|=12$ in the latter case.

${ }^{50} \mathrm{~A}$ root vertex is a vertex labeled in a special way so as to distinguish it from the other vertices. A graph with one or more root vertices is called a rooted graph.
} 
Remark. An interval composition $\alpha$ under the pitch operation $P_{x}$ is called a pitched interval composition $P_{x} \alpha$, and is equivalent to a pitch or pitch-class set $P=\left\{p_{1}, p_{2}, \ldots, p_{k}\right\}, P \subseteq V$, given respectively by $P=\left\{x+\sum_{i=1}^{j} \alpha_{i-1}\right\}_{j=1}^{k+1}$ or $\left\{\left(x+\sum_{i=1}^{j} \alpha_{i-1}\right) \bmod |E|\right\}_{j=1}^{k}$. Conversely, the pitched interval composition equivalent to a successively arranged ${ }^{51}$ pitch or pitch-class set $P=\left\{p_{1}, p_{2}, \ldots, p_{k}\right\}$, $P \subseteq V$, is given respectively by $P_{x} \alpha=P_{p_{1}}\left\langle p_{i+1}-p_{i}\right\rangle_{i=1}^{k-1}$ or $P_{p_{1}}\left\langle\left(p_{(i+1) \bmod k}-p_{i \bmod k}\right) \bmod |E|\right\rangle_{i=1}^{k}$, where $p_{0}=p_{k}$ in the latter case. The $x$ in $P_{x}$ is called the pitch index.

Ex. $P_{0}\langle 3,4,5\rangle= \begin{cases}\{0,3,7,12\}, & \text { for a cp-space, } \\ \{0,3,7\}, & \text { for a cpc-space. }\end{cases}$

$$
\begin{aligned}
& P_{9}\langle 1,1,2,1,3,1,3\rangle= \begin{cases}\{9,10,11,13,14,17,18,21\}, & \text { for a cp-space, } \\
\{9,10,11,1,2,5,6\}, & \text { for a cpc-space. }\end{cases} \\
& \{2,4,5,7,9\}= \begin{cases}P_{2}\langle 2,1,2,2\rangle, & \text { for a cp-space, } \\
P_{2}\langle 2,1,2,2,5\rangle, & \text { for a cpc-space. }\end{cases}
\end{aligned}
$$

Def. 4.2. Transposition $\left(T_{x}\right)$. Let $\alpha=\left\langle\alpha_{1}, \alpha_{2}, \ldots, \alpha_{k}\right\rangle$ be a pitched interval composition of a categorical pitch or pitch-class space $G=(V, E)$, the transposition operation is respectively defined by $T_{x} P_{y} \alpha=P_{x+y}\left\langle\alpha_{1}, \alpha_{2}, \ldots, \alpha_{k}\right\rangle$ or $P_{(x+y) \bmod |E|}\left\langle\alpha_{1}, \alpha_{2}, \ldots, \alpha_{k}\right\rangle$, where $x \in \mathbb{Z}$.

Remark. The transposition operation $T_{x}$ results in a translation or a rotation of the pitched interval composition $P_{y} \alpha$ by $x$, if $G$ is respectively a categorical pitch or pitch-class space. ${ }^{52}$ The $x$ in $T_{x}$ is called the transposition index. $T_{0}$ is an identity operation.

$$
\begin{gathered}
\text { Ex. } T_{2} P_{3}\langle 3,3,6\rangle= \begin{cases}P_{2+3}\langle 3,3,6\rangle=P_{5}\langle 3,3,6\rangle, & \text { for a cp-space, } \\
P_{(2+3) \bmod 12}\langle 3,3,6\rangle=P_{5}\langle 3,3,6\rangle, & \text { for a cpc-space. }\end{cases} \\
T_{8} P_{7}\langle 1,2,1,3,5\rangle= \begin{cases}P_{8+7}\langle 1,2,1,3,5\rangle=P_{15}\langle 1,2,1,3,5\rangle, & \text { for a cp-space, } \\
P_{(8+7)} \bmod 12\langle 1,2,1,3,5\rangle=P_{3}\langle 1,2,1,3,5\rangle, & \text { for a cpc-space. }\end{cases} \\
T_{-5} P_{2}\langle 2,1,2,3,4\rangle= \begin{cases}P_{-5+2}\langle 2,1,2,3,4\rangle=P_{-3}\langle 2,1,2,3,4\rangle, & \text { for a cp-space, } \\
P_{(-5+2) \bmod 12}\langle 2,1,2,3,4\rangle=P_{9}\langle 2,1,2,3,4\rangle, & \text { for a cpc-space. }\end{cases}
\end{gathered}
$$

Def. 4.3. Inversion $\left(\boldsymbol{I}, \boldsymbol{I}_{\boldsymbol{x}}\right)$. Let $\alpha=\left\langle\alpha_{1}, \alpha_{2}, \ldots, \alpha_{k}\right\rangle$ be an interval composition of a categorical pitch or pitch-class space $G=(V, E)$, the inversion operation is defined by $I \alpha=\left\langle\alpha_{k}, \alpha_{k-1}, \ldots, \alpha_{1}\right\rangle$. Remark. If $\alpha$ is pitched, then the transposition operation $T_{x}$ must be associated with the inversion operation $I$, resulting in the composite operation $T_{x} I$, abbreviated as $I_{x}$, such that $I_{x} P_{y} \alpha=$ $P_{x+y}\left\langle\alpha_{k}, \alpha_{k-1}, \ldots, \alpha_{1}\right\rangle$ or $P_{(x+|E|-y) \bmod |E|}\left\langle\alpha_{k}, \alpha_{k-1}, \ldots, \alpha_{1}\right\rangle$, if $G$ is respectively a categorical pitch or pitch-class space, where $x \in \mathbb{Z}$. The inversion operation $I_{x}$ results in a reflection of the pitched interval composition $P_{y} \alpha$ around an axis of symmetry $s=(x+y+|E|) / 2$ or $(x \bmod |E|) / 2$, if $G$ is respectively a categorical pitch or pitch-class space. The $x$ in $I_{x}$ is called the inversion index. $I_{0}$ is equivalent to $I$.

Ex. $I\langle 4,3,5\rangle=\langle 5,3,4\rangle$

$$
I_{9} P_{5}\langle 1,2,2,3,4\rangle= \begin{cases}P_{9+5}\langle 4,3,2,2,1\rangle=P_{14}\langle 4,3,2,2,1\rangle, & \text { for a cp-space, } \\ P_{(9+12-5) \bmod 12}\langle 4,3,2,2,1\rangle=P_{4}\langle 4,3,2,2,1\rangle, & \text { for a cpc-space. }\end{cases}
$$

\footnotetext{
${ }^{51}$ Unlike for a pitch set, "successively arranged" does not necessarily mean "arranged in ascending order" for a pitch-class set, but rather "arranged in cyclic order."

${ }^{52}$ In the former case, $G$ is also translated by $x$, such that $V=\left\{v_{i}+x\right\}_{i=1}^{n}$. In the latter case, it is the root vertex of $G$ that is rotated by $x$.
} 


$$
I_{-6} P_{10}\langle 1,2,1,1,2,5\rangle= \begin{cases}P_{-6+10}\langle 5,2,1,1,2,1\rangle=P_{4}\langle 5,2,1,1,2,1\rangle, & \text { for a cp-space } \\ P_{(-6+12-10) \bmod 12}\langle 5,2,1,1,2,1\rangle=P_{8}\langle 5,2,1,1,2,1\rangle, & \text { for a cpc-space. }\end{cases}
$$

Def. 4.4. Multiplication $\left(\boldsymbol{M}_{x}\right)$. Let $\alpha=\left\langle\alpha_{1}, \alpha_{2}, \ldots, \alpha_{k}\right\rangle$ be an interval composition of a categorical pitch or pitch-class space $G=(V, E)$, the multiplication operation is respectively defined by $M_{x} \alpha=\left\langle x \cdot \alpha_{1}, x \cdot \alpha_{2}, \ldots, x \cdot \alpha_{k}\right\rangle$ or $\left\langle\left|x \cdot \alpha_{k}\right|,\left|x \cdot \alpha_{k-1}\right|, \ldots,\left|x \cdot \alpha_{1}\right|\right\rangle$, for $x \geq 0$ or $x<0$, where $x \in \mathbb{Q}$.

Remark. If $\alpha$ is pitched and $G$ is a categorical pitch space, then $M_{x} P_{y} \alpha=P_{x \cdot y}\left\langle x \cdot \alpha_{1}, x \cdot \alpha_{2}, \ldots, x \cdot \alpha_{k}\right\rangle$ or $P_{x \cdot y}\left\langle\left|x \cdot \alpha_{k}\right|,\left|x \cdot \alpha_{k-1}\right|, \ldots,\left|x \cdot \alpha_{1}\right|\right\rangle$, respectively for $x \geq 0$ or $x<0$, where $x \in \mathbb{Q}$. If $\alpha$ is pitched and $G$ is a categorical pitch-class space, then $M_{x} P_{y} \alpha=P_{(x \cdot y) \bmod |E|}\left\langle x \cdot \alpha_{1}, x \cdot \alpha_{2}, \ldots, x \cdot \alpha_{k}\right\rangle$ or $P_{(x \cdot y) \bmod |E|}\left\langle\left|x \cdot \alpha_{k}\right|,\left|x \cdot \alpha_{k-1}\right|, \ldots,\left|x \cdot \alpha_{1}\right|\right\rangle$, respectively for $x \geq 0$ or $x<0$, where $x \in \mathbb{Q}$. The multiplication operation $M_{x}$ results in a homothety, i.e., a homogeneous dilation or contraction of the pitched interval composition $P_{y} \alpha$ by $x$, respectively if $|x|>1$ or $0<|x|<1$. The $x$ in $M_{x}$ is called the multiplication index. $M_{-1}$ is equivalent to the inversion operation $I . M_{0}$ results in an empty interval composition. $M_{1}$ is an identity operation.

Ex. $M_{5}\langle 2,3,2,1,4\rangle=\langle 10,15,10,5,20\rangle$

$$
\begin{aligned}
& M_{7} P_{3}\langle 2,1,3,6\rangle= \begin{cases}P_{7 \cdot 3}\langle 7 \cdot 2,7 \cdot 1,7 \cdot 3,7 \cdot 6\rangle=P_{21}\langle 14,7,21,42\rangle, & \text { for a cp-space, } \\
P_{(7 \cdot 3) \bmod 12}\langle 7 \cdot 2,7 \cdot 1,7 \cdot 3,7 \cdot 6\rangle=P_{9}\langle 14,7,21,42\rangle, & \text { for a cpc-space. }\end{cases} \\
& M_{-\frac{1}{3}} P_{6}\langle 3,9,24\rangle= \begin{cases}P_{-\frac{1}{3} \cdot 6}\left\langle\left|-\frac{1}{3} \cdot 24\right|,\left|-\frac{1}{3} \cdot 9\right|,\left|-\frac{1}{3} \cdot 3\right|\right\rangle=P_{-2}\langle 8,3,1\rangle, & \text { for a cp-space, } \\
P_{\left(-\frac{1}{3} \cdot 6\right) \bmod 12}\left\langle\left|-\frac{1}{3} \cdot 24\right|,\left|-\frac{1}{3} \cdot 9\right|,\left|-\frac{1}{3} \cdot 3\right|\right\rangle=P_{10}\langle 8,3,1\rangle, & \text { for a cpc-space. }\end{cases}
\end{aligned}
$$

Considering this is an introductory work, we will not go beyond the definitions of those so-called canonical operations-transposition, inversion, and multiplication-which are sufficient for now. Nevertheless, other operations (rotation, merge, split, transference, interference, conjugation, complementation, etc.) are in progress and will be properly formalized in due course.

\section{Musical Application}

Let's take as an example the musical miniature for piano shown in Figure 8, which was composed using the cyclic interval composition $\langle 3,1,4,4\rangle$ and the basic operations $\left(P_{x}, T_{x}, I_{x}, M_{x}\right)$. At first, we have $P_{2}\langle 3,1,4,4\rangle=\{2,5,6,10\}$ and its inversion $I_{0} P_{2}\langle 3,1,4,4\rangle=P_{10}\langle 4,4,1,3\rangle=\{10,2,6,7\}$, disposed respectively on outer and inner parts and transposed successively by $T_{-1}$ throughout the entire piece, except for mm. 5, where the outer parts are in turn multiplied by $M_{2} P_{11}\langle 3,1,4,4\rangle=$ $P_{10}\langle 6,2,8,8\rangle=\{10,4,6,2\}$, before completing the chromatic sequence a perfect fifth (P5) away from the starting point (i.e., $c i_{2-9}=c i_{10-5}=7$ ).

At first glance, it may seem that there is no significant difference between this approach and that used in pitch-class set theory, not least because the operations are basically the same. However, with a little more attention, we realize that the interval representation has great advantages for describing structural relationships, making them more explicit and comprehensible. In this sense, the interval structures and basic operations presented here are not only very useful, but alsopossibly-the first steps on a long journey towards the development of a post-tonal system, or rather, a post-tonal harmony. 


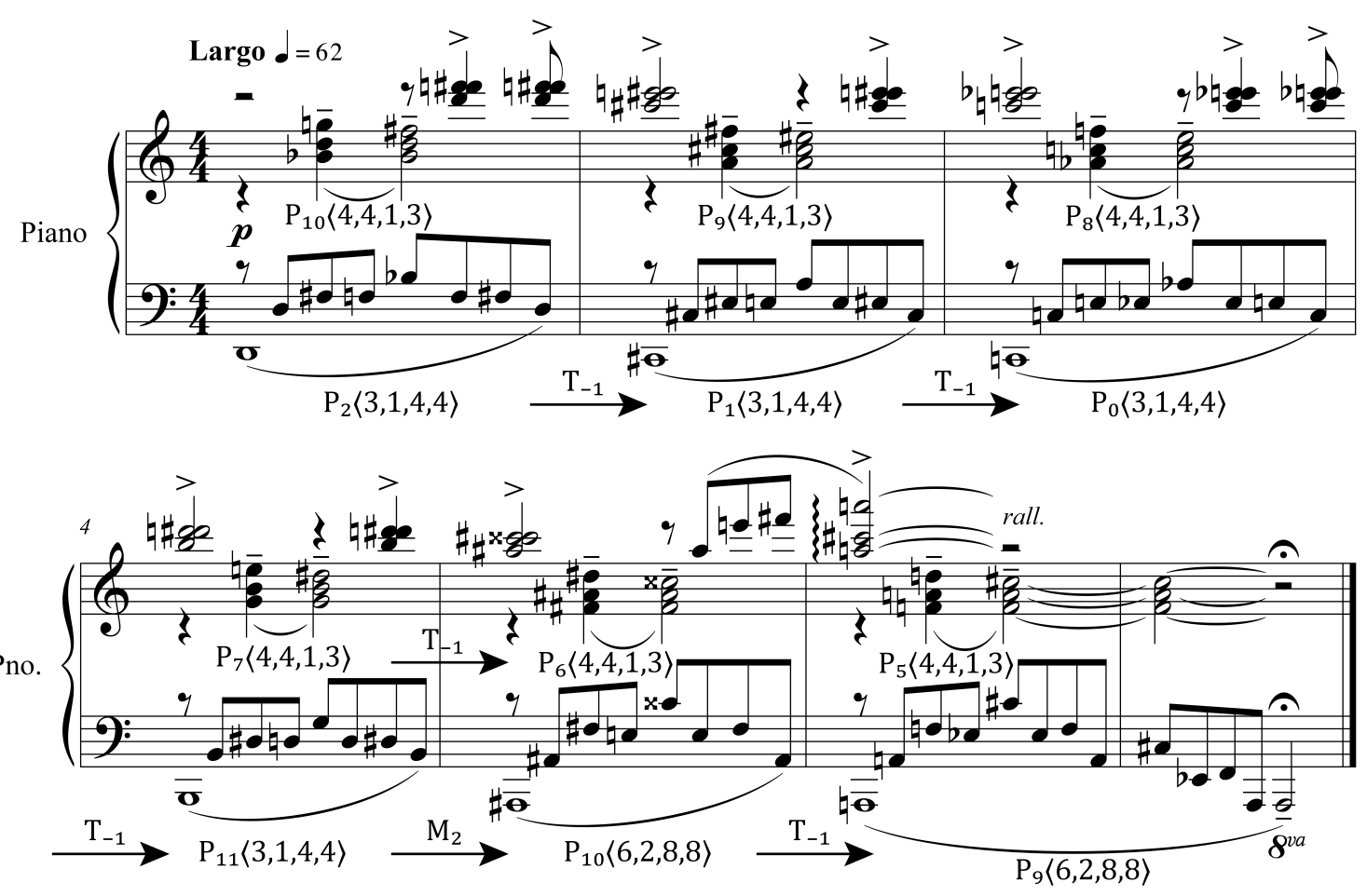

Figure 8: Musical miniature using the cyclic interval composition $\langle 3,1,4,4\rangle$ and the basic operations $\left(P_{x}, T_{x}, I_{x}, M_{x}\right)$.

\section{CONCLUding Remarks}

In this preliminary work, we have sought to present a brief historical review of the use of partitions in music, to provide a concise introduction to the theory of partitions, and lastly, through an extensive bibliographic revision and a thoughtful theoretical reflection, to lay the foundations of what we have called partitional harmony. As we could see, at least fundamentally, this conception runs through many subjects of post-tonal music theory and different fields of mathematics, presenting great potential for musical applications, whether analytical or compositional.

As we progress in our research, our theoretical scope will be gradually expanded, including other operations of transformation and ordering of the interval structures, enumeration of those structures, ${ }^{53}$ algorithms to normal and prime forms, new approaches to interval content (interval orbits, interval multicompositions and multipartitions), inclusion, similarity, and equivalence relations, harmonic identities, voice-leading spaces [28, 45, 121, 164], in addition to the development of an application software (a calculator) and an exhaustive taxonomy for interval structures. In the long run, the codification or systematization of the harmonic aspects of the post-tonal language through the use of partitions, or other partitional systems, ${ }^{54}$ may be a point of convergence between partitional analysis [66] and the modeling of compositional systems [134, 135].

Finally, we hope that many of the concepts and the valuable bibliography presented here will be useful to those interested in post-tonal music theory and related topics.

\footnotetext{
${ }^{53}$ For an introduction to enumeration in music, see [37, 60, 61, 62, 63, 73, 83, 87, 91, 143].

${ }^{54}$ Since the notion of categorical space may be extended to musical entities other than pitches or pitch-classes, such as chords, scales, harmonic progressions, etc., we can likewise partition those spaces and establish relationships between their elements through the use of partitions. Hence the concept of partitional systems.
} 


\section{REFERENCES}

[1] Alder, H. (1969) Partition Identities - From Euler to the Present. The American Mathematical Monthly, 76/7, pp. 733-746.

[2] Alegant, B. (1993) The Seventy-Seven Partitions of the Aggregate: Analytical and Theoretical Implications. Dissertation (PhD in Music), Eastman School of Music, University of Rochester.

[3] Alegant, B. (1996) Unveiling Schoenberg's Op. 33b. Music Theory Spectrum, 18/2, pp. 143-166.

[4] Alegant, B. (1999) When Even Becomes Odd: A Partitional Approach to Inversion. Journal of Music Theory, 43/2, pp. 193-230.

[5] Alegant, B. (2001) Cross-Partitions as Harmony and Voice Leading in Twelve-Tone Music. Music Theory Spectrum, 23/1, pp. 1-40.

[6] Alegant, B.; Mead, A. (2012) Having the Last Word: Schoenberg and the Ultimate Cadenza. Music Theory Spectrum, 34/2, pp. 107-136.

[7] American National Standards Institute (ANSI); Acoustical Society of America (ASA). 2013. American National Standard: Acoustical Terminology. ANSI/ASA S1.1-2013.

[8] Andrews, G. (1994) Number Theory. New York: Dover Publications.

[9] Andrews, G. (1998) The Theory of Partitions. Cambridge: Cambridge University Press.

[10] Andrews, G. (2008) A Survey of Multipartitions: Congruences and Identities. In: Alladi, Krishnaswami (ed.). Surveys in Number Theory. Developments in Mathematics, 17. New York: Springer, pp. 1-19.

[11] Andrews, G.; Eriksson, K. (2004) Integer Partitions. Cambridge: Cambridge University Press.

[12] Attneave, F.; Olson, R. (1971) Pitch as a Medium: A New Approach to Psychophysical Scaling. The American Journal of Psychology, 84/2, pp. 147-166.

[13] Babbitt, M. (1955) Some Aspects of Twelve-Tone Composition. The Score and I.M.A. Magazine, 12, pp. 53-61.

[14] Babbitt, M. (1960) Twelve-Tone Invariants as Compositional Determinants. Musical Quarterly, $46 / 2$, pp. 246-259.

[15] Babbitt, M. (1961) Set Structure as a Compositional Determinant. Journal of Music Theory, 5/1, pp. 72-94.

[16] Bachem, A. (1950) Tone Height and Tone Chroma as Two Different Pitch Qualities. Acta Psychologica, 7, pp. 80-88.

[17] Backus, J. (1969) The Acoustical Foundations of Music. New York: W. W. Norton \& Company.

[18] Bacon, E. (1917) Our Musical Idiom. The Monist, 27, pp. 560-607.

[19] Barbour, J. (2004) Tuning and Temperament: A Historical Survey. Mineola: Dover Publications.

[20] Bazelow, A.; Brickle, F. (1976) A Partition Problem Posed by Milton Babbitt (Part I). Perspectives of New Music, 14-15/2-1, pp. 280-293. 
[21] Benade, A. (2012) Fundamentals of Musical Acoustics. New York: Oxford University Press.

[22] Bender, E. (1978) An Introduction to Mathematical Modeling. New York: John Wiley \& Sons.

[23] Bender, E.; Canfield, E. (2005) Locally Restricted Compositions I. The Electronic Journal of Combinatorics, 12, Art. 57, pp. 1-27.

[24] Beranek, L. (1996) Acoustics. New York: Acoustical Society of America and American Institute of Physics.

[25] Bernard, J. (1997) Chord, Collection, and Set in Twentieth-Century Theory. In: Baker, James M.; Beach, David W.; Bernard, Jonathan W. (eds.). Music Theory in Concept and Practice. Rochester, NY: University of Rochester Press, pp. 11-51.

[26] Berry, W. (1987) Structural Functions in Music. New York: Dover Publications.

[27] Bertalanffy, L. (1969) General System Theory: Foundations, Development, Applications. New York: George Braziller.

[28] Bordini, R. (2018) Expanded Atonal Voice-Leading Space for Trichords: An Auxiliary Model for Generating Pre-Compositional Material. Musica Theorica, 3/1, pp. 108-127.

[29] Boretz, B. (1970) Sketch of a Musical System (Meta-Variations, Part II). Perspectives of New Music, 8/2, pp. 49-111.

[30] Boretz, B. (1971) Musical Syntax (II). Perspectives of New Music, 9-10/2-1, pp. 232-270.

[31] Boulez, P. (1971/1963) Boulez on Music Today. Translated by Susan Bradshaw and Richard Rodney Bennett. London: Faber \& Faber.

[32] Briley, P.; Breakey, C.; Krumbholz, K. (2013) Evidence for pitch chroma mapping in human auditory cortex. Cerebral Cortex, 23/11, pp. 2601-2610.

[33] Brower, C. (2008) Paradoxes of Pitch Space. Music Analysis, 27/1, pp. 51-106.

[34] Bruinier, J.; Ono, K. (2013) Algebraic formulas for the Coefficients of Half-Integral Weight Harmonic Weak Maass Forms. Advances in Mathematics, 246, pp. 198-219.

[35] Burns, E.; Ward, W. (1978) Categorical Perception-Phenomenon or Epiphenomenon: Evidence from Experiments in the Perception of Melodic Musical Intervals. The Journal of the Acoustical Society of America, 63/2, pp. 456-468.

[36] Burns, E.; Ward, W. (1982) Intervals, Scales, and Tuning. In: Deutsch, Diana (ed.). The Psychology of Music. New York: Academic Press, pp. 241-269

[37] Case, J.; Koban, L.; LeGrand, J. (2015). Counting Set Classes with Burnside's Lemma. Involve, 8/2, pp. 337-344.

[38] Carter, E. (2002) Harmony Book. New York: Carl Fischer.

[39] Chrisman, R. (1969) A Theory of Axis-Tonality For Twentieth-Century Music. Dissertation (PhD in Music), Faculty of the Graduate School, Yale University.

[40] Chrisman, R. (1971) Identification and Correlation of Pitch-Sets. Journal of Music Theory, 15/1-2, pp. 58-83. 
[41] Chrisman, R. (1977) Describing Structural Aspects of Pitch-Sets Using Successive-Interval Arrays. Journal of Music Theory, 21/1, pp. 1-28.

[42] Chrisman, R. (1979) Anton Webern's Six Bagatelles for String Quartet, Op. 9: The Unfolding of Intervallic Successions. Journal of Music Theory, 23/1, pp. 81-122.

[43] Clough, J.; Cuciurean, J.; Douthett, J. (1997) Hyperscales and the Generalized Tetrachord. Journal of Music Theory, 41/1, pp. 67-100.

[44] Clough, J.; Engebretsen, N.; Kochavi, J. (1999) Scales, Sets, and Interval Cycles: A Taxonomy. Music Theory Spectrum, 21/1, pp. 74-104.

[45] Coelho de Souza, R. (2018) Harmonic Perception and Voice Leading Spaces of Set Classes Related by Unordered Interval Classes. Musica Theorica, 3/2, pp. 46-85.

[46] Cogan, R.; Escot, P. (1976) Sonic Design: The Nature of Sound and Music. Englewood Cliffs: Prentice-Hall.

[47] Cundy, H.; Rollett, A. (1981) Mathematical Models. Norfolk: Tarquin Publications.

[48] Demany, L.; Armand, F. (1984) The Perceptual Reality of Tone Chroma in Early Infancy. The Journal of the Acoustical Society of America, 76/1, pp. 57-66.

[49] Deutsch, D. (1978) The Psychology of Music. In: Carterette, E.; Friedman, M. (eds.). Handbook of Perception, 10. New York: Academic Press, pp. 191-224.

[50] Deutsch, D. (1982) The Processing of Pitch Combinations. In: Deutsch, D. (ed.). The Psychology of Music. New York: Academic Press, pp. 271-316.

[51] Douthett, J.; Hyde, M.; Smith, C. (eds.) (2008) Music Theory and Mathematics: Chords, Collections, and Transformations. Rochester: University of Rochester Press.

[52] Dym, C. (2004) Principles of Mathematical Modeling. Burlington: Elsevier Academic Press.

[53] Euler, L. (1988/1990[1748]) Introduction to Analysis of the Infinite: Book I/II. Translated by J. D. Blanton. New York: Springer.

[54] Fayers, M. (2006) Weights of Multipartitions and Representations of Ariki-Koike Algebras. Advances in Mathematics, 206, pp. 112-144.

[55] Folsom, A.; Kent, Z.; Ono, K. (2012) $\ell$-Adic Properties of the Partition Function. Advances in Mathematics, 229, pp. 1586-1609.

[56] Forte, A. (1964) A Theory of Set-Complexes for Music. Journal of Music Theory, 8/2, pp. 136-183.

[57] Forte, A. (1973a) The Basic Interval Patterns. Journal of Music Theory, 17/2, pp. 234-272.

[58] Forte, A. (1973b) The Structure of Atonal Music. New Haven: Yale University Press.

[59] Forte, A. (1988) Pitch-Class Set Genera and the Origin of Modern Harmonic Species. Journal of Music Theory, 32/2, pp. 187-270.

[60] Fripertinger, H. (1992) Enumeration in Musical Theory. Beiträge zur Elektronischen Musik, 1, Graz: Hochschule für Musik und Darstellende Kunst. 
[61] Fripertinger, H. (1999a) Enumeration of Mosaics. Discrete Mathematics, 199, pp. 49-60.

[62] Fripertinger, H. (1999b) Enumeration and Construction in Music Theory. In: Feichtinger, Hans G.; Dörfler, M. (eds.). Computational and Mathematical Methods in Music, pp. 179-204. Vienna: Österreichische Computer Gesellschaft.

[63] Fripertinger, H. (2004) Tiling Problems in Music Theory. In: Mazzola, Guerino; Noll, Thomas; Lluis-Puebla, Emilio (eds.). Perspectives in Mathematical and Computational Music Theory. Osnabrück: epOs Music, pp. 153-168.

[64] Fripertinger, H.; Lackner, P. (2015) Tone Rows and Tropes. Journal of Mathematics and Music, 9/2, pp. 111-172.

[65] Gamer, C. (1967) Some Combinational Resources of Equal-Tempered Systems. Journal of Music Theory, 11/1, pp. 32-59.

[66] Gentil-Nunes, P. (2009) Análise particional: uma mediação entre composição musical e a teoria das partições. Tese (Doutorado em Música), Centro de Letras e Artes, Universidade Federal do Estado do Rio de Janeiro.

[67] Gentil-Nunes, P. (2017) Partitiogram, Mnet, Vnet and Tnet: Embedded Abstractions Inside Compositional Games. In: Pareyon, G.; et al (eds.). The Musical-Mathematical Mind: Patterns and Transformations. Berlin: Springer, pp. 111-118.

[68] Gentil-Nunes, P. (2018) Nestings and Intersections between Partitional Complexes. MusMat: Brazilian Journal of Music and Mathematics, 2/1, pp. 93-108.

[69] Gentil-Nunes, P.; Carvalho, A. (2003) Densidade e linearidade na configuração de texturas musicais. In: Colóquio de Pesquisa do Programa de Pós-Graduação em Música da UFRJ, 4. , Anais.... Rio de Janeiro: Universidade Federal do Rio de Janeiro, pp. 40-49.

[70] Giordano, F.; Fox, William P.; Horton, S. (2014) A First Course in Mathematical Modeling. Boston: Brooks/Cole, Cengage Learning.

[71] Goldstone, R.; Hendrickson, A. (2010) Categorical Perception. WIREs Cognitive Science, 1/1, pp. 69-78.

[72] Goldstone, R.; Kersten, A.; Carvalho, P. (2018) Categorization and Concepts. In: Wixted, J.; Thompson-Schill, S. (eds.). Stevens' Handbook of Experimental Psychology and Cognitive Neuroscience, 3. New York: John Wiley \& Sons, pp. 275-317.

[73] Graham, J.; Hack, A.; Wilson, J. (2008) An Application of Burnside's Theorem to Music Theory. The UMAP Journal, 29/1, pp. 45-57.

[74] Grimaldi, R. (2003) Discrete and Combinatorial Mathematics: An Applied Introduction. Boston: Pearson.

[75] Guo, Y. (2018) Some Identities for Palindromic Compositions. Journal of Integer Sequences, 21, Art. 18.6.6, pp. 1-9.

[76] Guo, Y.; Munagi, A. (2017) Inverse-Conjugate Compositions into Parts of Size at Most $k$. Online Journal of Analytic Combinatorics, 12, pp. 1-12.

[77] Haimo, E.; Johnson, P. (1984) Isomorphic Partitioning and Schoenberg's Fourth String Quartet. Journal of Music Theory, 28/1, pp. 47-72. 
[78] Hanson, H. (1960) Harmonic Materials of Modern Music: Resources of the Tempered Scale. New York: Appleton-Century-Crofts.

[79] Hardy, G.; Ramanujan, S. (1918) Asymptotic Formulæ in Combinatory Analysis. Proceedings of the London Mathematical Society, s2-17/1, pp. 75-115.

[80] Hardy, G.; Wright, E. (2008) An Introduction to the Theory of Numbers. Oxford: Oxford University Press.

[81] Harley, M. (1994) Space and Spatialization in Contemporary Music: History and Analysis, Ideas and Implementations. Dissertation (PhD. in Music), McGill University.

[82] Haynes, B.; Cooke, P. (2001) Pitch. Grove Music Online. https://www. oxfordmusiconline.com/grovemusic/view/10.1093/gmo/9781561592630.001.0001/ omo- $9781561592630-\mathrm{e}-0000040883$.

[83] Hook, J. (2007) Why Are There Twenty-Nine Tetrachords? A Tutorial on Combinatorics and Enumeration in Music Theory. Music Theory Online, 13/4. https://mtosmt.org/issues/mto. 07.13.4/mto.07.13.4.hook.html.

[84] Hoong, L.; Kin, H.; Pien, C. (2015) Concrete-Pictorial-Abstract: Surveying its Origins and Charting its Future. The Mathematics Educator, 16/1, pp. 1-18.

[85] Howe, H. (1965) Some Combinational Properties of Pitch Structures. Perspectives of New Music, 4/1, pp. 45-61.

[86] James, R. (1992) Mathematics Dictionary. New York: Chapman \& Hall.

[87] Jedrzejewski, F. (2006) Mathematical Theory of Music. Sampzon: Delatour France/Ircam-Centre Pompidou.

[88] Johnson, T. (2008) Foundations of Diatonic Theory: A Mathematically Based Approach to Music Fundamentals. Lanham: Scarecrow Press.

[89] Justus, T.; Bharucha, J. (2002) Music Perception and Cognition. In: Pashler, H.; Yantis, S. (eds.). Stevens' Handbook of Experimental Psychology. Vol. 1: Sensation and Perception. New York: John Wiley \& Sons, pp. 453-492.

[90] Kalman, D. (1997) Elementary Mathematical Models: Order Aplenty and a Glimpse of Chaos. Washington: The Mathematical Association of America.

[91] Keith, M. (1991) From Polychords to Pólya: Adventures in Musical Combinatorics. Princeton: Vinculum Press.

[92] Klein, M.; Zatorre, R. (2011) A Role for the Right Superior Temporal Sulcus in Categorical Perception of Musical Chords. Neuropsychologia, 49/5, pp. 878-887.

[93] Klir, G. (2001) Facets of Systems Science. New York: Springer Science / Business Media.

[94] Knobloch, E. (2002) The Sounding Algebra: Relations Between Combinatorics and Music from Mersenne to Euler. In: Assayag, G.; Feichtinger, H.; Rodrigues, J. (eds). Mathematics and Music: A Diderot Mathematical Forum. Berlin: Springer, pp. 27-48.

[95] Knopfmacher, A.; Robbins, N. (2010) Some Properties of Cyclic Compositions. The Fibonacci Quarterly, 48/3, pp. 249-255. 
[96] Krumhansl, C. (2001) Cognitive Foundations of Musical Pitch. New York: Oxford University Press.

[97] Kurth, R. (1992) Mosaic Polyphony: Formal Balance, Imbalance, and Phrase Formation in the Prelude of Schoenberg's Suite, Op. 25. Music Theory Spectrum, 14/2, pp. 188-208.

[98] Kurth, R. (1993) Mosaic Isomorphism and Mosaic Polyphony: Balance and Imbalance in Schoenberg's Twelve-Tone Rhetoric. Dissertation (PhD. in Music), Harvard University.

[99] Kurth, R. (1996) Dis-Regarding Schoenberg's Twelve-Tone Rows: An Alternative Approach to Listening and Analysis for Twelve-Tone Music. Theory and Practice, 21, pp. 79-122.

[100] Kurth, R. (1999) Partition Lattices in Twelve-Tone Music: An Introduction. Journal of Music Theory, 43/1, pp. 21-82.

[101] Langner, G. (2015) The Neural Code of Pitch and Harmony. Cambridge: Cambridge University Press.

[102] Lerdahl, F. (1988) Tonal Pitch Space. Music Perception, 5/3, pp. 315-349.

[103] Lerdahl, F. (2004) Tonal Pitch Space. New York: Oxford University Press.

[104] Lewin, D. (2007/1987) Generalized Musical Intervals and Transformations. Oxford: Oxford University Press.

[105] Loy, G. (2006) Musimathics: The Mathematical Foundations of Music, 1. Cambridge: The MIT Press.

[106] Mansour, T. (2012) Combinatorics of Set Partitions. Boca Raton: CRC Press.

[107] Martinez, F.; et al. (2018) Teoria dos números: um passeio com primos e outros números familiares pelo mundo inteiro. Rio de Janeiro: IMPA.

[108] Martino, D. (1961) The Source Set and its Aggregate Formations. Journal of Music Theory, $5 / 2$, pp. 224-273.

[109] Mazzola, G. (2002) The Topos of Music: Geometric Logic of Concepts, Theory, and Performance. Basel: Birkhäuser.

[110] Mead, A. (1988) Some Implications of the Pitch Class/Order Number Isomorphism Inherent in the Twelve-Tone System: Part One. Perspectives of New Music, 26/2, pp. 96-163.

[111] Mead, A. (1989) Some Implications of the Pitch-Class/Order-Number Isomorphism Inherent in the Twelve-Tone System: Part Two: The Mallalieu Complex: Its Extensions and Related Rows. Perspectives of New Music, 27/1, pp. 180-233.

[112] Meadows, D. (2009) Thinking in Systems: A Primer. London: Earthscan.

[113] Merlini, D.; Uncini, F. Verri, M. (2004) A Unified Approach to the Study of General and Palindromic Compositions. Integers: Electronic Journal of Combinatorial Number Theory, 4, Art. 23, pp. 1-26.

[114] Miller, J. (1978) Living Systems. New York: McGraw-Hill. 
[115] Moerel, M.; De Martino, F.; Santoro, R.; Yacoub, E.; Formisano, E. (2015) Representation of Pitch Chroma by Multi-Peak Spectral Tuning in Human Auditory cortex. NeuroImage, 106, pp. 161-169.

[116] Mooney, K. (2001) Tonal Space. Grove Music Online. https://www. oxfordmusiconline.com/grovemusic/view/10.1093/gmo/9781561592630.001.0001/ omo-9781561592630-e-0000042826.

[117] Morris, R. (1982-1983) Combinatoriality without the Aggregate. Perspectives of New Music, 21/1-2, pp. 432-486.

[118] Morris, R. (1987) Composition with Pitch-Classes: A Theory of Compositional Design. New Haven: Yale University Press.

[119] Morris, R. (1991) Class Notes for Atonal Music Theory. Lebanon: Frog Peak Music.

[120] Morris, R. (1995) Equivalence and Similarity in Pitch and Their Interaction with PCSet Theory. Journal of Music Theory, 39/2, pp. 207-243.

[121] Morris, R. (1998) Voice-Leading Spaces. Music Theory Spectrum, 20/2, pp. 175-208.

[122] Morris, R. (2003) Pitch-Class Duplication in Serial Music: Partitions of the Double Aggregate. Perspectives of New Music, 41/2, pp. 96-121.

[123] Morris, R.; Alegant, B. (1988) The Even Partitions in Twelve-Tone Music. Music Theory Spectrum, 10, pp. 74-101.

[124] Morris, R.; Starr, D. (1974) The Structure of All-Interval Series. Journal of Music Theory, 18/2, pp. 364-389.

[125] Munagi, A. (2013) Primary Classes of Compositions of Numbers. Annales Mathematicae et Informaticae, 41, pp. 193-204.

[126] Munagi, A. (2018) Integer Compositions and Higher-Order Conjugation. Journal of Integer Sequences, 21, Art. 18.8.5, pp. 1-22.

[127] Nolan, C. (2000) On Musical Space and Combinatorics: Historical and Conceptual Perspectives in Music Theory. In: Sarhangi, Reza (ed.). Bridges: Mathematical Connections in Art, Music, and Science. Winfield: Bridges Conference, pp. 201-208.

[128] Oliveira, J. (2016) Teoria Analítica da Música no Século XX. Lisboa: Fundação Calouste Gulbenkian.

[129] Perle, G. (1954) The Possible Chords in Twelve-Tone Music. The Score and I.M.A. Magazine, 9, pp. 54-58.

[130] Perle, G. (1957) Review: George Rochberg: The Hexachord and its Relation to the TwelveTone Row. Journal of the American Musicological Society, 10, 1, pp. 55-59.

[131] Perle, G. (1991/1962) Serial Composition and Atonality: An Introduction to the Music of Schoenberg, Berg and Webern. Berkeley: University of California Press.

[132] Perle, G. (1996/1977) Twelve-Tone Tonality. Berkeley: University of California Press.

[133] Pikler, A. (1966) Logarithmic Frequency Systems. The Journal of the Acoustical Society of America, 39/6, pp. 1102-1110. 
[134] Pitombeira, L. (2018) A Systemic Model for Debussy's Prelude No. 1. MusMat: Brazilian Journal of Music and Mathematics, 2/2, pp. 37-57.

[135] Pitombeira, L. (2020) Compositional Systems: Overview and Applications. MusMat: Brazilian Journal of Music and Mathematics, 4/1, pp. 39-62.

[136] Plack, C.; Oxenham, A.; Fay, R.; Popper, A. (eds.) (2005) Pitch: Neural Coding and Perception. New York: Springer.

[137] Rademacher, H. (1938) On the Partition Function $p(n)$. Proceedings of the London Mathematical Society, s2-43/1, pp. 241-254.

[138] Rademacher, H. (1943) On the Expansion of the Partition Function in a Series. Annals of Mathematics, Second Series, 44/3, pp. 416-422.

[139] Rahn, J. (1979-1980) Relating Sets. Perspectives of New Music, 18/1-2, pp. 483-498.

[140] Rahn, J. (1980) Basic Atonal Theory. New York: Longman.

[141] Rakowski, A. (2009) The Domain of Pitch in Music. Archives of Acoustics, 34/4, pp. 429-443.

[142] Regener, E. (1974) On Allen Forte's Theory of Chords. Perspectives of New Music, 13/1, pp. 191-212.

[143] Reiner, D. (1985) Enumeration in Music Theory. The American Mathematical Monthly, 92/1, pp. 51-54.

[144] Révész, G. (1954) Introduction to the Psychology of Music. Norman: University of Oklahoma Press.

[145] Rosch, E. (1978) Principles of Categorization. In: Rosch, E.; Lloyd, B. (eds.). Cognition and Categorization. Hillsdale: Lawrence Erlbaum, pp. 27-48.

[146] Rothenberg, D. (1978a) A Model for Pattern Perception with Musical Applications. Part I: Pitch Structures as Order-Preserving Maps. Mathematical Systems Theory, 11, pp. 199-234.

[147] Rothenberg, D. (1978b) A Model for Pattern Perception with Musical Applications. Part II: The Information Content of Pitch Structures. Mathematical Systems Theory, 11, pp. 353-372.

[148] Rothenberg, D. (1978c) A Model for Pattern Perception with Musical Applications. Part III: The Graph Embedding of Pitch Structures. Mathematical Systems Theory, 12, pp. 73-101.

[149] Sillitto, H.; et al. (2017) Defining "System": a Comprehensive Approach. INCOSE International Symposium, 27/1, pp. 170-186.

[150] Schuijer, M. (2008) Analyzing Atonal Music: Pitch-Class Set Theory and Its Contexts. Rochester: University of Rochester Press.

[151] Semal, C.; Demany, L. (1990) The Upper Limit of Musical Pitch. Music Perception: An Interdisciplinary Journal, 8/2, pp. 165-175.

[152] Sethares, W. (2005) Tuning, Timbre, Spectrum, Scale. London: Springer-Verlag.

[153] Shepard, R. (1965) Approximation to Uniform Gradients of Generalization by Monotone Transformations of Scale. In: Mostofsky, D. (ed.). Stimulus Generalization. Stanford: Stanford University Press, pp. 94-110. 
[154] Shepard, R. (1982) Structural Representations of Musical Pitch. In: Deutsch, D. (ed.). The Psychology of Music. New York: Academic Press, pp. 344-390.

[155] Soderberg, S. (1995) Z-Related Sets as Dual Inversions. Journal of Music Theory, 39/1, pp. $77-100$.

[156] Soderberg, S. (2008) Transformational Etudes: Basic Principles and Applications of Interval String Theory. In: Douthett, Jack; Hyde, Martha M.; Smith, C. (eds.). Music Theory and Mathematics: Chords, Collections, and Transformations. Rochester: University of Rochester Press, pp. 222-244.

[157] Sousa, D. (2015) Perspectivas para a análise textural a partir da mediação entre a teoria dos contornos e a análise particional. Dissertação (Mestrado em Música), Universidade Federal do Rio de Janeiro.

[158] Sousa, D. (2017) Textural Contour: A Proposal for Textural Hierarchy Through the Ranking of Partitions lexset. In: Pareyon, G.; et al (eds.). The Musical-Mathematical Mind: Patterns and Transformations. Berlin: Springer, pp. 199-206.

[159] Sousa, D. (2019) Composing with Textures: A Proposal for Formalization of Textural Spaces. MusMat: Brazilian Journal of Music and Mathematics, 3/1, pp. 19-48.

[160] Stanley, R. (2012) Enumerative Combinatorics. Vol. 1. Cambridge Studies in Advanced Mathematics. Cambridge: Cambridge University Press.

[161] Starr, D. (1978) Sets, Invariance and Partitions. Journal of Music Theory, 22/1, pp. 1-42.

[162] Starr, D.; Morris, R. (1977) A General Theory of Combinatoriality and the Aggregate (Part 1). Perspectives of New Music, 16/1, pp. 3-35.

[163] Starr, D.; Morris, R. (1978) A General Theory of Combinatoriality and the Aggregate (Part 2). Perspectives of New Music, 16/2, pp. 50-84.

[164] Straus, J. (2005) Voice Leading in Set-Class Space. Journal of Music Theory, 49/1, pp. 45-108.

[165] Straus, J. (2016) Introduction to Post-Tonal Theory. New York: W. W. Norton \& Company.

[166] Toussaint, G. (2013) The Geometry of Musical Rhythm: What Makes a "Good" Rhythm Good? Boca Raton: CRC Press.

[167] Tymoczko, D. (2011) A Geometry of Music: Harmony and Counterpoint in the Extended Common Practice. New York: Oxford University Press.

[168] Ueda, K.; Ohgushi, K. (1987) Perceptual Components of Pitch: Spatial Representation Using a Multidimensional Scaling Technique. The Journal of the Acoustical Society of America, 82/4, pp. 1193-1200.

[169] Vuza, D. (1991) Supplementary Sets and Regular Complementary Unending Canons (Part One). Perspectives of New Music, 29/2, pp. 22-49.

[170] Ward, W. (1970) Musical Perception. In: Tobias, Jerry V. (ed.). Foundations of Modern Auditory Theory, 1. New York: Academic Press, pp. 407-447.

[171] Ward, W.; Burns, E. (1982) Absolute Pitch. In: Deutsch, D. (ed.). The Psychology of Music. New York: Academic Press, pp. 431-451. 
[172] Warren, J.; Uppenkamp, S.; Patterson, R.; Griffiths, T. (2003) Separating Pitch Chroma and Pitch Height in the Human Brain. Proceedings of the National Academy of Sciences of the United States of America, 100/17, pp. 10038-10042.

[173] Weisstein, E. (2020a) Partition. MathWorld - A Wolfram Web Resource. http://mathworld. wolfram.com/Partition.html.

[174] Weisstein, E. (2020b) Partition Function P. MathWorld - A Wolfram Web Resource. http: //mathworld.wolfram.com/PartitionFunctionP.html.

[175] Wintle, C. (1976) Milton Babbitt's Semi-Simple Variations. Perspectives of New Music, 14-15/21, pp. 111-154.

[176] Xenakis, I. (1992) Formalized Music: Thought and Mathematics in Composition. Stuyvesant: Pendragon Press. 